\title{
SOCIEDADE DE RISCO, DIREITO PENAL E POLÍTICA CRIMINAL
}

\author{
RISK SOCIETY, CRIMINAL LAW AND CRIMINAL POLICYINAL
}

Eduardo Diniz Neto ${ }^{1}$

RESUMO: O presente artigo respeita ao "novo direito penal" no contexto de uma sociedade contemporânea globalizada caracterizada como uma "sociedade de riscos", a exigir sua intervenção em searas nunca antes imaginadas pelo direito penal clássico, as quais são objetiva e subjetivamente amplificadas e potencializadas por diversos fatores, dentre os mais proeminentes, o progresso tecnológico, o desenvolvimento do conhecimento e "a força dos poderosos" num mundo dominado pelas leis do mercado e da eficiência econômica. Trata, portanto, deste direito penal moderno e sua missão de, a par da proteção de bens jurídicos tradicionais, simultaneamente se voltar para a tutela de novos bens jurídico-penais peculiares da sociedade pós-industrial, também sob o enfoque da política criminal.

Palavra-Chave: Direito Penal; Crise; Política Criminal; Sociedade de risco.

ABSTRACT: The following scientific article regards to the "new criminal law" into a globalized and contemporary society, characterized as a "risky society", that demands its intervention in fields never wondered before by classical criminal law, which are objective and subjectivelly increased and potentialized by many sources, mainly technological progress, knowledge development and the "powerfull's strength" in a world dominated by market rules and economic eficiency. Therefore, the article faces this modern criminal law and its simultaneous mission, as time as protects traditional legal wills, to defend those new wills raised upon a post-industry society, also in a criminal policy perspective.

Palavra-Chave: Criminal Law; Crisis; Criminal Policy; Risky society.

\section{INTRODUÇÃO}

O tema do presente trabalho respeita ao "novo direito penal" no contexto de uma sociedade contemporânea globalizada caracterizada como uma "sociedade de riscos", a exigir sua intervenção em searas nunca antes imaginadas pelo direito penal clássico, as quais são objetiva e subjetivamente amplificadas e potencializadas por diversos fatores, dentre os mais proeminentes, o progresso tecnológico, o desenvolvimento do conhecimento e a força dos "poderosos" num mundo dominado pelas leis do mercado e da eficiência econômica ("neoliberalismo").

1 Professor do Departamento de Direito Público da Universidade Estadual de Londrina e Promotor de Justiça. 
Tratar-se-á, portanto, deste direito penal moderno e sua missão de, a par da proteção de bens jurídicos tradicionais, simultaneamente se voltar para a tutela de novos bens jurídicopenais peculiares da sociedade pós-industrial, tarefa que implica na revisão de muitos de seus fundamentos de ordem dogmático-jurídica e das posturas político-criminais ainda hoje, sob muitos aspectos, em voga.

Para tanto, imprescindível incorrermos - sem perder de vista a atemporal, posto que ainda aplicável aos nossos dias, definição de "política criminal" de Feuerbach - pelo conjunto representativo de procedimentos através dos quais, dentro de diversas tendências, o corpo social virtualmente organiza as respostas ao fenômeno criminal, não só no âmbito do direito penal, passando, necessariamente, também por políticas públicas de inclusão social e mudança de paradigmas culturais.

Sob o ponto de vista político-criminal, na atualidade, não resta dúvida de que o direito penal continua a figurar como a mais grave forma de intervenção estatal diante do indivíduo, o que leva, por um lado, para muitos, à imperiosa necessidade de reforço paradigmático do denominado "direito penal mínimo".

Isto porque a crise do pensamento ressocializador relativamente às consequências jurídicas do delito, a saber, as sanções de natureza penal - nomeadamente a mais tradicional delas, a prisão -, desencadeou o surgimento de propostas genuinamente abolicionistas ou, numa perspectiva menos radical, reducionistas do sistema penal. Como se verá, as propostas reducionistas gravitam ao redor de dois aspectos principais: a alternativa despenalizadora e a realocação do papel da vítima como protagonista no contexto do conflito penal.

No entanto, a sociedade moderna, paradoxalmente, diante do atual estágio de evolução tecnológico-industrial, científica e econômica, passou a conviver com uma série de condutas atentatórias a bens jurídicos inalcançáveis pela forma de tutela de um dito direito penal clássico, situação que exige, por conseguinte, a modernização de seu complexo normativo-coercitivorepressivo, sem o que não há como se legitimar a intervenção deste ramo do direito para a solução de conflitos ou mesmo como instrumento de defesa social ou da ordem pública. Numa aproximação, assim, com a própria teoria da sociedade, situada entre o plano da fundamentação e o plano de aplicação do direito penal, a dinâmica da "sociedade do risco" é conduzida por uma racionalidade instrumental (econômica, técnica e científica), com viés, muitas vezes, marginal aos discursos moral e ético, que é responsável pelo surgimento de novos e grandes riscos e sua potencial dimensão de catastrófica. "Na verdade, as sociedades contemporâneas têm vindo a ser confrontadas e a adquirir progressivamente consciência de que o progresso tecnológico, cientí- 
fico e econômico que assenta o seu desenvolvimento, a par de inúmeros benefícios, produz graves ameaças para a existência e a qualidade da vida humana" (SILVA DIAS, 2008, p. 21-22).

Diante das contingências desse novo dirigismo da "sociedade de riscos", ou seja, dentro de um contexto de exigências da própria modernização do direito penal, recrudesce, para muitos críticos, a crença na capacidade de intimidação pelas penas, revalorizando-se o escopo, principalmente, da prevenção geral através das sanções de natureza penal frente a condutas de determinados grupos de pessoas, representativos de verdadeiras "fontes de perigo" e que, por isso mesmo, devem ser neutralizados a qualquer custo (“direito penal do inimigo"), sem se priorizar, ou mesmo a desprezar totalmente, o caráter preventivo especial (ressocialização).

Portanto, o atual debate sobre a legitimidade do direito penal está centrado no binômio reducionismo garantista e expansão, dentro do contexto - e lógica tensão dialética - de exigências da modernização do direito penal e, concomitantemente, preservação de garantias fundamentais do cidadão.

\section{PRINCIPAIS POSTURAS POLÍTICO-CRIMINAIS FRENTE À CRISE RESSOCIALI- ZADORA DO DIREITO PENAL}

Com a crise ressocializadora do Direito Penal, surgem, num primeiro momento e mais acentuadamente a partir da primeira metade do século XX, posturas político-criminais de índole amplamente restritiva no tocante à sua intervenção para a solução de conflitos sociais ou mesmo, na moderna concepção, para a tutela de bens jurídicos. Dentre elas, destacam-se o abolicionismo, a opção reducionista e a opção garantística ou garantista.

\section{O abolicionismo}

O abolicionismo (na sua feição mais radical, denominado de "utópico") teve por fundamento, essencialmente, as construções teoréticas de autores como Louk Hulsman, Neils Christie, Mathiesen e Foucault.

Permeia, esta postura político-criminal, ora um sentido amplo, ora um sentido mais restrito.

No seu sentido amplo e extremado - tendo por base a teorizações da criminologia radical, que desqualifica totalmente o sistema penal -, apregoa a abolição conjuntural do sistema penal, a ponto de sugerir sua total substituição por outras formas de intervenção estatal ou, de 
qualquer outra forma, reconhecidas como jurídicas na solução de conflitos relativos às lesões ou ameaças de dano a bens relevantes em sociedade, mediante sanções tradicionalmente concebidas como de natureza extrapenal, mormente indenizatórias ou reparatórias (CRESPO, 2004, p. 14-18). Confronta-se, assim, como se verá à frente, com o abolicionismo institucional e com o chamado reducionismo penal (direito penal mínimo).

$\mathrm{Na}$ vertente restrita e menos radical, entretanto, traz a ideia de abolição de algum aspecto concreto do sistema penal, numa perspectiva abolicionista institucional, como se dá, v.g., no tocante a determinadas espécies de penas ou outras instituições penais segregatórias. A propósito, existem, mundo afora, registros históricos de diversos movimentos abolicionistas precedentes, como no caso da abolição da escravatura, das penas corporais, da pena de morte, etc..

Em qualquer que seja seu sentido, no entanto, o abolicionismo entende o sistema penal como um autêntico mal à sociedade, na medida em que configura resposta violenta e pública ao fenômeno delituoso, suscetível também de incitar maior violência, porquanto cria e alimenta a falsa sensação de proporcionar, às vítimas, ajuda e proteção, levando à frustração e ao perigoso descrédito no próprio sistema.

Na sua genérica acepção, ainda, concebe o delito como uma situação problemática, uma realidade que só aqueles diretamente implicados - ou seja, autor, vítima ou seus representantes - conhecem. Em outras palavras, os protagonistas do delito são dotados da disposição fenomenológica para a compreensão das coisas, que, por conseguinte, somente pode ser qualificada e solucionada a partir da visão que a consciência dos componentes do grupo afetado tem da mesma, o que leva, ao fim e ao cabo, à negação do monopólio da solução do conflito pelo Estado.

Reclama, em suma, um entendimento totalmente diferente do universo penal a partir de três idéias exponenciais: a) o dano e sua compensação; b) a sobrevalorização dos conflitos como antagonismos interpessoais; e c) a priorização de acordos no processo penal, de modo a reivindicar a devolução dos conflitos aos seus diretamente implicados, todos, inclusive vítima, tratados como protagonistas do fenômeno.

Obviamente que essa proposta abolicionista, tanto mais na sua vertente radical, sofreu e ainda sofre críticas de diversas ordens, desde aquelas de cunho científico, passando pelas de cunho garantista, até ao criminológico, levando-a ao quase total ostracismo ante a superação por outras correntes epistemológicas.

Com efeito, seus críticos apontam, sob o primeiro aspecto científico, a inconsistência de suas bases e propostas, já que parte para a construção de uma política criminal eminente- 
mente irregular. O Abolicionismo é, segundo aqueles, dentro da perspectiva da teoria do conhecimento, um método que, de acordo com a concepção de Heidegger, entraria em uma relação dialética com o seu objeto. Assim, sendo o método a luta pela abolição de todo o sistema penal, este teria, paradoxalmente, por objeto o sistema penal que busca eliminar, sem pretender, em momento algum, uma reconciliação entre o intelecto e o status quo (CRESPO, 2004, p. 18).

A principal crítica de cunho garantista prende-se na constatação de que a abolição do direito penal implica na diluição simultânea de seus limites, que pode conduzir à instauração do caos, de uma sociedade disciplinar sem controle ou de controles quase ilimitados face à ausência de garantias.

Por fim, sob o ponto de vista criminológico, destaca-se criticamente que não há evidências mínimas, qualquer que seja a sociedade, de que esta queira prescindir da ideia de retribuição, a par da coexistência auspiciosa da ressocialização, pelo contrário: a ideia de abolição do castigo não satisfaz a grande maioria dos contextos sociais, concluindo-se que este é ainda um imperativo categórico para muitos, cuja inexistência poderia levar igualmente a uma temerária insatisfação dos cidadãos.

\section{O reducioniso}

O reducionismo - para alguns uma espécie ou ramificação do abolicionismo em sentido restrito -, tem por traços característicos, em síntese, a aceitação da existência do sistema penal, buscando, porém, alternativas realistas à sua atual configuração, fundadas numa concepção das instituições com espírito humanista.

Nesse afã, preconiza alternativas ao atual sistema, estabelecendo novos paradigmas, fundados na dignidade da pessoa humana, para - tão mais acentuadas, quanto sejam possíveis e recomendáveis -, a descriminalização de condutas, a despenalização e a descarcerização, bem como buscando uma verdadeira justiça penal consensual, como técnica alternativa para a solução de conflitos desse gênero.

Trata-se de corrente da política criminal que dirige severas críticas ao arrefecimento punitivo quanto à pena privativa de liberdade e, segundo seus adeptos, a utilização e manipulação das vítimas para que o poder estatal possa reivindicar o programa político-criminal maximalista subjacente, como se o direito penal pudesse, por si só e onipotentemente, com a pena (castigo), restaurar a "justiça material". 
Especificamente quanto à pena privativa de liberdade, considera que a prisão opera como fator criminógeno, uma vez que a subcultura das masmorras, com a privação até mesmo de mínimos prazeres, gera uma autêntica psicose carcerária, de modo a inviabilizar o cumprimento dos fins de prevenção geral e de prevenção especial, como concebidos sob a ótica dos clássicos do direito penal. Acentua, ainda, essa postura político-criminal, tal qual já o fazia Von Liszt ao seu tempo, a inocuidade das penas privativas de liberdade de curta duração .

Indica como motivos ensejadores da imperiosa necessidade de redução do uso da pena privativa de liberdade, portanto - a par dos questionamentos acerca da desproporcionalidade e consequente abuso no uso das penas de longa duração em determinados casos -, o fato de esta consubstanciar efetiva causa do incremento tanto da criminalização primária , quanto da criminalização secundária, além de que a reclusão, comprovadamente, em nada contribui para a almejada ressocialização do sentenciado, dentro daquilo que se convenciona comumente chamar de "crise do pensamento ressocializador".

O reducionismo, assim, concebe o direito penal como um direito de garantias, cuja aplicação surge calcada, precipuamente, em uma série de princípios fundamentais irrenunciáveis, hauridos do contexto histórico-social e com assento constitucional, com base nos quais é levado a buscar alternativas válidas para a pena privativa de liberdade, enquanto esta continue a ser imprescindível ao sistema penal frente à gravidade das condutas perpetradas contra determinados e extremamente valiosos bens jurídicos.

Esta corrente não perde de vista, contudo, que toda a política criminal que pretende limitar a intervenção penal deve vir acompanhada de políticas sociais de transformação das estruturas sócio-econômicas.

Num particular aspecto que, sem confundi-lo, o aproxima de uma das ideias fundantes do abolicionismo, o reducionismo igualmente prega a priorização de acordos no processo penal, de modo a reivindicar a devolução dos conflitos aos seus diretamente implicados, atribuindo à vítima o papel de figura central do fenômeno delituoso. Sob influência da vitimologia norteamericana, sobretudo desde a década de 60 do século passado, introduz a vítima no conflito penal, compreendendo o delito como drama humano com dois pólos antagônicos protagonistas, numa real modificação, face às correntes clássicas, do objeto e da orientação da criminologia, com naturais conseqüências para o âmbito da política criminal e dogmática penal, dentre elas a discussão dos problemas atinentes à reparação de danos ao ofendido e à compensação entre autor e vítima, para o que se destacam instrumentos alternativos cada vez mais recorrentes, como o caso da mediação penal, por muitos considerada o principal instrumento da justiça 
restaurativa, que, por sua vez, é também apontada como uma verdadeira alternativa ao sistema penal (SANTOS, 2006, p. 85-91).

Atribui, assim, uma perspectiva horizontal ao delito - tendente a evitar, outrossim, a denominada vitimização secundária (SANTOS, 2006) -, e procura se impor como resposta à atual crise da política criminal, que surge, como visto, ante o ceticismo reinante quanto às possibilidades de prevenção do direito penal.

Através dessa perspectiva horizontal do delito, contrapõe-se, o reducionismo, à tradicional perspectiva do crime, fundada em um conflito essencialmente bilateral e vertical entre o Estado e o indivíduo responsável penal, segundo a qual somente têm relevância e por essa razão são reconhecidos como elementos do sistema penal, a "gravidade do fato" e o "caráter público do conflito penal", tudo a acentuar, ao fim e ao cabo, a exclusiva titularidade do jus puniendi pelo ente estatal.

Contudo, os críticos dessa perspectiva horizontal do delito desde sempre apresentam um seu nó górdio, que consignamos para as devidas reflexões, na medida em que, segundo os mesmos, a partir do processo histórico que procedeu a uma estrita separação entre o direito penal e o direito civil, resulta muito difícil situar e conciliar a exclusiva reparação no direito penal material com o clássico sistema dos fins das penas.

\section{O garantismo}

O garantismo representa possivelmente o paradigma de referência para todas as propostas reducionistas, pois não aborda a questão da legitimação do direito penal a partir de uma perspectiva parcial, mas a partir de uma visão global dos fundamentos dessa legitimação, numa conotação externa e interna, vale dizer, "a questão do se e do por que punir", afastando-se, neste particular, do mero neoproporcionalismo, que se ocupa tão-só da questão de como punir, tomando-o como momento de exclusiva legitimação interna do direito penal (CRESPO, 2004, p. 24-28).

Apontado como o principal autor dessa postura político-criminal, Luigi Ferrajoli tornase paradigma mundial do denominado direito penal mínimo, consagrando o garantismo como verdadeira realização do programa iluminista (FERRAJOLI, 1997). Na base de sua concepção garantística, circunscreve o direito penal a um "mínimo necessário" para evitar a violência social informal, como possíveis reações punitivas espontâneas dos cidadãos agredidos, com o que se afasta abissalmente das teses abolicionistas mais radicais. 
Com efeito, o garantismo de Ferrajoli se auto-situa como meio-termo entre o abolicionismo e o autoritarismo. Segundo o próprio autor em evidência, assim o é porque se trata o abolicionismo de standard de uma sociedade selvagem, enquanto que o totalitarismo consubstancia o modelo da sociedade disciplinar, pacificadora e totalizadora, na qual os conflitos são controlados e resolvidos mediante mecanismos ético-pedagógicos de interiorização da ordem ou de tratamento médico, ou de panoptismo social e, inclusive, policial (FERRAJOLI, 1997, p. 251).

Destaca-se, no garantismo, sua aproximação de uma criminologia crítica, encarada como uma "carga de justificação desse produto humano e artificial que é o direito penal", além da revalorização do pensamento utilitarista proveniente da ilustração dos enciclopedistas, na defesa da plena vigência de todas as garantias do direito penal liberal, à luz das exigências do Estado de Direito.

E para a consecução deste paradigma utilitarista, existem condições a materializar os limites ou proibições como garantias do cidadão contra o arbítrio ou o erro punitivo (decálogo ou "dez mandamentos" de Ferrajoli), consubstaciados em princípios fundamentais (e constitucionais) penais e processuais penais, como legalidade; lesividade; alteridade; proporcionalidade; individualidade; culpabilidade; dignidade da pessoa humana (intervenção mínima); fragmentariedade (e corolários da taxatividade e da subsidiariedade); devido processo legal; contraditório e ampla defesa (FERRAJOLI, 1997, p. 103).

Portanto, este "modelo de Direito Penal do Estado de Direito" representa gênero de ordenamento no qual o poder público, e especificamente o poder punitivo, está rigidamente limitado e vinculado à lei no plano substancial (ou dos conteúdos penalmente relevantes) e no plano processual (ou das formas processualmente vinculantes). Para além disso, encontra sua dimensão substancial e concreta não só nas condições de validade das normas, mas também na natureza da própria democracia.

\section{O DIRETO PENAL NA SOCIEDADE DE RISCO: O EXPANSIONISMO.}

Modernamente, os entendimentos teóricos já abordados - notadamente o reducionismo e o garantismo - coexistem e se confrontam com uma realidade empírica que toma, cada vez mais, rumo diametralmente oposto àquele referenciado contexto de um "direito penal mínimo", que é a expansão do âmbito do punível, caracterizadora, portanto, do denominado expansionismo do direito penal. 
Em outras palavras, poderíamos dizer que o que está em confronto é o pensamento teórico catalisador do direito penal clássico (Kernstrafrecht), com maior representatividade, hoje, pela Escola de Frankfurt, e o substrato fático-teórico do chamado "novo direito penal" (direito penal “acessório"), dirigido à proteção de bens jurídicos característicos e peculiares da sociedade pós-industrial.

Surge este novo direito penal, portanto, no contexto de uma sociedade contemporaneamente caracterizada como uma "sociedade de riscos" e sua crescente dinâmica instrumentalizada racionalmente por hegemônicos paradigmas tecnológicos, científicos e econômicos, a exigir a intervenção penal em terrenos nunca antes imaginados por aquele direito penal clássico e sua concepção eminentemente individualista (sob o ponto de vista do contexto das ações intersubjetivas), personalista (no sentido do princípio societas delinquere non potest) e garantista (com a observância de condições que dão concretude aos limites ou proibições como garantias do cidadão contra o arbítrio ou o erro punitivo do Estado) (DIAS, 2001, p. 155).

O que confere, assim, à sociedade moderna o predicado de uma sociedade de riscos - a ensejar novos contornos a vários ramos do direito, dentre eles também o direito penal -, é o complexo conjunto de peculiaridades levado a efeito, principalmente, pelo progresso tecnológico e pelo desenvolvimento do conhecimento hoje alcançado num mundo globalizado e seus lógicos consectários do aumento das interconexões causais e da substituição dos contextos de ação individuais por contextos de ação coletivos (BECK, 2002) - , ou seja, a substituição do contato interpessoal por uma forma de comportamento anônima e padronizada, "estandardizada", na ofensa ou periclitação de bens jurídicos de natureza preponderantemente supra ou metaindividual, com repercussões, portanto, igualmente muito mais alargadas e potencialmente lesivas.

Essa nova realidade do "risco" tem levado ao fenômeno da "inflação punitiva", como a mais relevante e, segundo os críticos do expansionismo, intolerável consequência de suas peculiaridades no âmbito do direito penal. E intolerável porque se evidencia a incapacidade do direito penal clássico para solucionar os problemas decorrentes dessa proliferação legislativa indiscriminada, levando, por outro lado, à necessidade de mudanças no sistema que, ao menos aparentemente, poderiam ferir preceitos garantísticos irrenunciáveis dos cidadãos.

O "novo direito penal” decorrente da necessidade de mudanças do paradigma clássico para o enfrentamento da novel realidade fenomêmica da criminalidade surgida com a "sociedade de riscos", nessa orientação, mais se aproxima das bases epistemológicas ditas funcionalistas ou normativistas, plasmadas entre as suas principais vertentes sistêmica (JAKOBS, 2000 e 2003) e teleológica (ROXIN, 2002). 
Em linhas gerais, costuma-se apontar três grandes traços da modernização ou expansão do direito penal, o primeiro e o último deles fruto direto dessa influência funcionalista, também chamada mais propriamente - para não inseri-la no mesmo contexto epistemológico, por exemplo, do neokantismo normativista, até porque este remonta historicamente a período não coincidente com a denominada moderna sociedade de risco - de neonormativista, a saber: a) a administrativização do direito penal; b) a regionalização ou globalização do direito penal; e c) a progressiva desconstrução do paradigma liberal do direito penal.

O fenômeno da administrativização do direito penal caracteriza-se, eminentemente, pela combinação de fatores como a introdução de novos objetos de proteção, a antecipação das fronteiras de proteção penal e a transição definitiva do modelo de "delito de lesão de bens individuais" para o modelo de "delito de perigo de bens supra-individuais", nas acepções já analisadas.

A regionalização ou globalização do direito penal leva em conta a nova criminalidade decorrente de fatores criminógenos vertidos da sociedade moderna - de cunho, primário ou secundário, eminentemente econômico -, cujos autores pertencem a e se valem de organismos de poder de caráter regional interno de um país, ou transnacional para suas empreitadas sem fronteiras, no combate à qual, mais eficazmente, deve-se operar aquele que resulta também num moderno fenômeno jurídico-político, que é a integração igualmente supranacional do aparato normativo e de forças de segurança/persecução oficiais, naquilo que configura um quadro de policentralidade dos poderes, que podem ser trans-estaduais, supra-estaduais (internacionais ou euro-comunitários, p. ex.) e infra-estaduais, sem desprezar, por outro lado, ainda - logicamente que com incidência muito mais restrita no âmbito criminal -, a pluralização e privatização das administrações públicas e o contributo das organizações sociais em proliferação.

Finalmente, o traço marcante da progressiva desconstrução do paradigma liberal do direito penal praticamente sintetiza toda a base epistemológica desse novo ordenamento jurídico-penal, amparada que está, essa desconstrução, para além de na já referida criação de novos bens jurídico-penais, na ideia central da ampliação dos espaços de risco jurídico-penalmente relevantes e consequentes flexibilização das regras de imputação e relativização dos princípios político-criminais de garantia (CRESPO, 2004, p. 28-30).

$\mathrm{Na}$ base da concepção funcionalista, portanto, a perspectiva do risco vincula-se com uma série de fenômenos afetos ao moderno direito penal, na medida em que este intervém em novos âmbitos cuja regulamentação pressupõe juízos de valor eminentemente normativos. Com efeito, de modo a ressaltar, outrossim, o traço da administrativização do direito penal e a 
frequente e imprescindível utilização de juízos de valor normativos para a própria compreensão do delito e sua imputação, vemos este ramo do direito a regular, antes mesmo de qualquer dano, setores de risco socialmente mais significativos no mundo moderno, como, v.g, a energia nuclear, o meio ambiente, a produção alimentícia, as investigações biomédicas, o sistema financeiro, etc, para o que se vale necessariamente, amiúde, de leis ou normas penais em branco ou abertas.

Nessa perspectiva, identifica-se o direito penal da sociedade de risco com a proliferação de delitos de perigo, ou seja, com a incriminação de condutas de risco, sem esperar a produção efetiva de danos, lesões ou de morte, para o que são erigidos a bens jurídico-penais aqueles cuja regulação e tutela se davam, noutros tempos, através de distintos ramos do direito, notadamente administrativo e civil. Essa proliferação, por sua vez, é indissociável do pensamento nuclear de segurança extraído da própria lei e da interpretação daqueles bens jurídicos supraindividuais, tal qual ocorre com relação, v.g., à segurança no tráfego, no trabalho, na saúde pública, etc.

A par disso, verifica-se a "modernização" dos pressupostos materiais e subjetivos da responsabilidade (imputação objetiva), com um novo desenvolvimento dogmático-jurídico da responsabilidade pelos delitos de ação, de omissão e culposos (MIRANDA-PEDRO, 2007, p. 8-22). Surge, assim, um novo discurso, baseado em uma crítica dogmático-filosófica, cuja pretensão derradeira seria interpretar os conceitos e os princípios jurídico-penais no contexto do materialismo da História. "A totalidade dos princípios, dos critérios político-criminais e dos instrumentos dogmáticos da modernização está ajustada às exigências do Estado de Direito”, de modo que "essa conformidade realiza-se em um grau tão absoluto que não admite nem exceções, nem uma mínima relativização”, nas palavras de Gracia Martín (CRESPO, 2004, p. 31).

Uma política criminal que pretendesse, assim, dar resposta a essa sociedade de risco poderia convocar-se a partir de quatro grandes linhas: Primeiramente, uma notável ampliação dos âmbitos sociais objeto de intervenção penal, a qual pretenderia incidir sobre realidades sociais preexistentes, cuja vulnerabilidade se tivesse potenciado; entre os setores de intervenção preferenciais teria de se citar a produção e distribuição de produtos, o meio ambiente, os novos âmbitos tecnológicos como o nuclear, o informático, o genético..., a ordem sócio-econômica e as atividades enquadradas em estruturas organizadas de crime, com especial menção ao tráfico ilícito de drogas. Em segundo lugar, uma significativa transformação do objetivo da nova política criminal, que concentraria seus esforços em perseguir a criminalidade dos poderosos, únicos setores sociais capazes de desenvolver sofisticadas condutas delituosas e que até então raramente entravam em contato com a justiça penal; para tais efeitos contar-se-ia com o aval 
derivado das demandas de intervenção penal vindas das organizações sociais surgidas nos últimos tempos em defesa dos novos interesses sociais - associações, ONGs, etc. -, com a decidida inserção nos programas de propostas de criminalização dessas atividades lesivas dos poderosos e, sobretudo, com o apoio das maiorias sociais que se identificam com as vítimas dos abusos dos socialmente privilegiados. Em terceiro lugar, a primazia dada à intervenção penal em detrimento de outros instrumentos de controle social, na crença de que a contundência e capacidade socializadora do direito criminal são mais eficazes na prevenção dessas condutas do que outras medidas de política econômica ou social, ou do que intervenções levadas a efeito no âmbito de outros setores jurídicos como o direito civil ou o direito administrativo, numa clara restrição ao princípio da subsidiariedade penal, que é, assim, posto em causa. Por fim, a necessidade de adaptar os conteúdos de direito penal e processual penal às dificuldades especiais à persecução desta nova criminalidade reporta ao problema de às novas técnicas do crime, aos obstáculos para determinar os riscos não permitidos, e à trabalhosa individualização de responsabilidades ter de se contrapor uma atualização dos instrumentos punitivos, o que implica em reconsiderar ou flexibilizar o sistema de imputação da responsabilidade e de garantias individuais vigentes, o que há-de fazer-se em função da necessidade político-criminal de melhorar a efetividade na perseguição e no processo penais (RIPOLLÉS, 2007, p. 547).

Conclui-se, em termos de delineamentos finais da postura político-criminal expansionista, que o papel regulador básico neste novo direito penal é o conceito de "risco permitido", que, no entanto, não é possível reduzir a um único momento categorial do delito, ou sequer a um único momento do processo de valoração jurídico-penal da conduta, pois pode atuar em todos eles, seja, por exemplo, como "causa de exclusão geral do desvalor da conduta", seja como “tópico da argumentação jurídico-penal na esfera da antijuridicidade ou ilicitude", porquanto se trata de critério que expressa, sempre, uma ponderação de todos os interesses jurídico-penalmente relevantes. Contrariamente, se o "risco for para além do permitido" e atingir esses bens jurídicos relevantes para o direito penal, este intervirá para sua tutela, ainda que, como visto, antecipadamente a qualquer dano concreto.

\section{Expansionismo versus reducionismo garantista.}

Como já se pôde constatar a partir de tímidas incursões ao longo do presente trabalho nesse sentido, ou mesmo intuitivamente, inúmeras são as críticas que afloram frente ao denominado expansionismo penal fundado nos entendimentos teóricos identificados com o funcionalis- 
mo ou neonormativismo no âmbito das ciências jurídico-criminais, elaboradas, essencialmente, pelos adeptos e defensores do direito penal mínimo e seu substrato reducionista/garantista, que os aproxima, por seu turno, do chamado direito penal clássico.

Essas críticas estão mesmo no centro e no cerne do debate sobre o perfil e o papel do direito penal nessa nova "sociedade de risco" ou "sociedade pós-industrial".

Desde logo, ácidas e pontuais críticas recebe a construção ideológica da ampliação dos espaços de risco jurídico-penalmente relevantes e consequentes flexibilização das regras de imputação e relativização dos princípios político-criminais de garantia, que poderiam levar, assim, à justificação, por exemplo, do denominado "direito penal do inimigo", na acepção concebida por Jakobs (JAKOBS, 2003, p. 42).

Nesse domínio, também conhecido como "discurso da resistência", a pretexto do eficaz enfrentamento a determinadas e específicas formas de criminalidade da modernidade, atinentes a matérias de incidência muito peculiares e de extrema e latente potencialidade lesiva (terrorismo; tráfico; imigração, etc), seus autores (ou virtuais autores) são tratados como meras "fontes de perigo", os quais devem, por conseguinte, ser, a todo e qualquer custo, neutralizados e retirados do convívio social.

Para tanto, e conforme aquela que é apontada como principal característica desta postura político-criminal, o direito penal do inimigo permite um amplo adiantamento da punibilidade, através da adoção de uma perspectiva fundamentalmente prospectiva, levando, em síntese, a um notável incremento das penas e à redução ou, se necessário ainda, à supressão de garantias processuais individuais(JAKOBS, 2003, p.37).

Como marcantes tendências ou pólos em seus regulamentos, sustenta Jakobs, em complemento àquela antecipação da punibilidade, um trato diferenciado com relação ao "cidadão" e ao "inimigo", na medida em que aquele é encarado como tal (efetivo cidadão) quando sua conduta se subsume à estrutura normativa da sociedade, enquanto que este, o inimigo, sequer pode figurar ou ser incluído dentre os tutelados por uma constituição cidadã, devendo, o tanto quanto possível e recomendável, ser interceptado previamente e assim combatido por sua injustificável periculosidade e, ainda que atávica, danosidade social.

Criticamente, portanto, o "direito penal do inimigo" surge como conseqüência direta da hodierna crise do direito penal, embalado por uma fé inquebrantável na capacidade de intimidação das penas, a ponto de abandonar o princípio básico do "direito penal do fato" (clássico) e se aproximar do totalitário "direito penal do autor" (combate a determinado grupo de pessoas). 
É consectário, outrossim, na acepção mais negativa do termo, do uso simbólico do direito penal - ou seja, aquele que persegue fins distintos da proteção de bens jurídicos no marco constitucional e de uma defesa social e da ordem pública sob o mesmo referencial garantístico -, além de efeito da própria crise do Estado de Direito, que propicia o aumento do recrudescimento punitivo estatal, ao alvedrio das vagas da demagogia política e do espetáculo midiático.

Pertinentemente à administrativização do direito penal que desencadeia, como visto, dentre outros fenômenos - a partir, notadamente, da criação de novos bens jurídico-penais e da ampliação dos espaços de risco e regras de imputação correspondentes -, a transposição do modelo de "delito de lesão a bens jurídicos individuais" para o modelo de "delito de perigo de bens supraindividuais", a crítica nodal assenta na constatação de que a incriminação de condutas sem levar em consideração, frequentemente, o critério do dano social do fato, na busca de exasperado pragmatismo de eficiência, por si só, pode levá-lo (o direito penal) a perder sua feição garantística, afrontando diversos princípios fundamentais constitucionais, dentre os quais, nomeadamente, neste caso, os princípios da lesividade, da alteridade e da proporcionalidade.

Seja qual for, no entanto, o aspecto pontual desse novo direito penal criticamente analisado, o que se sobreleva, sempre, é o conjunto de distorções e disfunções de um sistema que, sob muitos aspectos, nomeadamente no campo do "direito penal do inimigo", ainda está por surgir ou surge de forma embrionária, lembrando que, ao menos na realidade ocidental, salvo raras e notórias exceções teratológicas, o ordenamento jurídico infra-constitucional e sua interpretação submete-se aos fundamentos condicionantes existenciais e de aplicabilidade da Lei Maior e seus irrenunciáveis princípios garantísticos, a começar pelo primado da dignidade da pessoa humana.

O debate antecipado, contudo, é sempre o mais bem-vindo, pois cautelarmente pode originar soluções conciliatórias, tendentes à elisão ou superação de crises, a bem da efetiva tutela dos relevantes bens jurídicos em jogo, do convívio social minimamente ordeiro, pacífico, respeitoso e, sobretudo, digno. É a última tarefa que nos cabe na etapa conclusiva dessas anotações.

\section{CONCLUSÃO}

O "novo direito penal", cujos contornos foram panoramicamente visitados neste despretensioso trabalho, expande-se a partir de exigências de sua intervenção para a tutela de modernos bens jurídico-penais, produto da denominada "sociedade de riscos". 
Trata-se de uma realidade empírica crescente - visível quando nos deparamos, ilustrativamente, com a admissibilidade e regulamentação, ainda que restritas a determinadas e específicas tipologias, da responsabilização penal da pessoa jurídica (PRADO, 2001) ou coletiva - como, v.g., nos crimes ambientais (SILVA DIAS, 2008, p. 112) -, ou com a possibilidade de se estender a responsabilização penal com a ampliação da concorrência subjetiva no âmbito do punível, nomeadamente no que tange à imputação de resultados obtidos a partir de ações culposas ou omissões relevantes, flexibilizando-se, para tanto, princípios fundamentais até então concebidos como intocáveis por um direito penal na sua feição clássica e que, para muitos, em contrapartida, ainda devem prevalecer, sob pena de inconstitucionalidade dos dispositivos normativos que os confrontarem, posto que irrenunciáveis.

A dicotomia acima consignada, entretanto, é só mais um exemplo dos aparentemente intermináveis e inconciliáveis pontos nevrálgicos e de tensão dialética entre o direito penal em expansão (e sua base funcionalista) e os entendimentos teóricos reducionistas/garantistas, que levam, no contexto da sociedade pós-industrial, à insustentabilidade do direito penal sem uma profunda e sistemática revisão de seus fundamentos, acentuadamente de ordem conceitualanalítica (no âmbito das categorias ou elementos constitutivos do delito) e político-criminal.

Desde logo, no entanto, deve-se ter em mente que a solução desse conflito somente poderá ser obtida a partir daqueles dois pontos epistemológicos distintos, já tratados em seus contornos básicos no decorrer do trabalho, sem perder de vista que, como adverte Schünemann (CRESPO, 2004, p. 30-31), a adoção exclusiva de um ou outro modelo no atual contexto histórico conduz a um impasse obstaculizante à própria legitimidade e eficácia do direito penal. Isto porque, a prevalecer o modelo personalista ou individualista e liberal da escola clássica, cair-se-ia num ciclo repetitivo incessante de um mesmo genérico conjunto de princípios garantistas ("discurso fácil"), que, antes de se afigurar como elemento positivo para a tutela penal, converte-se no seu verdadeiro e intransponível obstáculo, pois, como visto, facilmente poderse-ia invocá-los, com todos os consectários inviabilizadores da intervenção penal, ainda que necessária. Por outro lado, com a incidência única do modelo funcionalista expansionista do "novo direito penal", chegar-se-ia a uma capitulação incondicional perante a prática política dominante, em cada momento, na atividade do legislador ou da jurisprudência, a constituir perigosa discricionariedade e tênue linha divisória entre a legalidade sem ou com arbítrio. 
O que fazer, então, para que o direito penal reencontre seu ponto de sustentação, que mudanças podem e devem ser promovidas ao longo deste caminho de mão única e incontornável de expansão que se vislumbra com a "sociedade de riscos"?

A via de solução possível, mais comumente referenciada pela doutrina, perpassa as linhas gerais, num futuro não muito remoto, de um chamado "direito penal de dupla velocidade" para o enfrentamento eficaz dos novos fenômenos delituosos, englobando aspectos jurídicopolíticos modificadores das teorias do delito e da pena.

A opção viável, nesse sentido, em síntese, seria a setorização das regras da parte geral do direito penal, em detrimento da modificação das regras que regem as modalidades clássicas de delinqüência como decorrência da poderosa força atrativa da nova criminalidade, uma vez que ambas as hipóteses são excludentes entre si. Ou seja, ao invés de uma reformulação da parte geral do direito penal para adaptá-la aos contornos funcionalistas - sujeita, como se vê, a toda sorte de críticas e seus próprios "riscos" -, sobrepondo-se, assim, ao clássico direito penal garantístico, continuaria, este, com suas atuais e irretocadas feições, a regular as modalidades de delinquência identificadas como tradicionais sob todos os aspectos principiológicos fundamentais, a par do que uma nova regulação seria desenvolvida - sem, contudo, abandonar preceitos garantísticos mínimos, quando muito os flexibilizar -, para abarcar e arrostar a moderna criminalidade, irrefreável tão-somente com os instrumentos à disposição do primeiro modelo.

Nessa perspectiva conciliatória e de coexistência neo-emancipatória do direto penal, portanto, pode-se criticamente concluir:

- A sociedade de riscos vem gerando um alarme social que está a provocar a expansão do direito penal, o que acarreta, por seu turno, determinados custos que afetam as garantias tradicionais do Estado de Direito, seja numa órbita geral de restrição, ou, na melhor das hipóteses, de reinterpretação das garantias clássicas do direito penal.

- A modernização do direito penal é necessária e, ao mesmo tempo, incontrolável, à vista das atuais interconexões causais e subjetivas, que tornam os problemas de nosso tempo muito diferentes daqueles nos quais se situam as origens do direito penal clássico (século XVIII).

- Vivemos em tempos de igual e crescente modernização da criminalidade, a qual conduz, inexoravelmente, a uma mudança quanto à sua abordagem jurídica e político-criminal, a fim de alcançar a denominada "criminalidade dos poderosos", e não só aos marginalizados menos favorecidos. 
- Inegável resulta, assim, na proteção dos bens jurídicos supra-individuais, a legitimidade $a b$ initio da existência e maior incidência de delitos de perigo, afastando-se daquilo que Roxin, neste particular, chama de "ceticismo infundado" (CRESPO, 2004, p. 35).

- Para que a "modernização" do direito penal reflita uma sua verdadeira "evolução", deve-se buscar o sempre recomendável equilíbrio nas imprescindíveis mudanças, as quais deverão ser empreendidas em escrupulosa obediência às garantias do estado de direito, e não sob o influxo de exigências sociais de segurança, carecedoras, muitas vezes, de critérios mínimos de razoabilidade a respeito da intervenção do direito penal.

- Enfim, o desafio maior da atual sociedade de risco é a construção de um sistema garantista dentro dessas novas realidades de intervenção do direito penal.

\section{REFERÊNCIA}

AMBOS, Kai. Da "teoria do delito" de BELING ao conceito de delito no direito penal internacional. Revista Portuguesa de Ciência Criminal, Coimbra, ano 16, n. 3, p. 363-384, 2006.

BECK, Ulrich. La sociedad del riesgo - hacia uma nueva modernidad. Trad. Jorge Navarro et al. Barcelona: Paidós, 2002.

BOBBIO, Norberto. Liberalismo e democracia. Trad. Marco Aurélio Nogueira. São Paulo: Brasiliense, 1994.

BONAVIDES, Paulo. Reflexões. Política e Direito. 3. ed. São Paulo: Malheiros, 1998.

CAMPILONGO, Celso Fernandes. O Direito na sociedade complexa. São Paulo: Max Limonad, 1998.

CANOTILHO, J. J. Gomes. Direito constitucional e teoria da constituição. 2. ed. Coimbra: Almedina, 1998.

CANOTILHO, J. J. Gomes; MOREIRA, Vital. Constituição da República Portuguesa Anotada. 1. ed. brasileira. 4. ed. portuguesa rev. Coimbra: Coimbra Editora, 2007.

COSTA, José Francisco de Faria. O perigo em direito penal: contributo para a sua fundamentação e compreensão dogmáticas. Coimbra: Coimbra Editora, 1992.

CRESPO, Eduardo Demetrio. Do direito penal liberal ao direito penal do inimigo. Revista da Associação Brasileira de Professores de Ciências Penais, São Paulo, ano 1, v. 1, p. 9-37, 2004. 
DIAS, Jorge de Figueiredo. O direito penal na $<<$ sociedade do risco $>>$. Temas básicos da doutrina penal. Coimbra: Coimbra Editora, 2001.

Resultados y problemas en la construcción de um sistema de derecho penal funcional y "racionalmente final". Fundamentos de um sistema europeu del derecho penal. Librohomenaje a Claus Roxin.. Barcelona: Bosch, 1995.

e ANDRADE, Manuel da Costa. Criminologia: O homem delinquente e a sociedade criminógena. 2. reimpressão. Coimbra: Coimbra, 1997.

DREIFUSS, René Armand. A época das Perplexidades: mundialização, globalização e planetarização - novos desafios. 2. ed. Petrópolis: Vozes, 1997.

FARIA, José Eduardo. Poder e Legitimidade. Uma Introdução à Política do Direito. São Paulo: Perspectiva, 1978.

FERRAJOLI, Luigi. Derecho y razón. Teoria del garantismo penal.. Trad. Perfecto Andrés Ibañez et al. Madrid: Trotta, 1997.

HABERMAS, Jurgen. Direito e Democracia: entre facticidade e validade. V. I e II. Rio de Janeiro: Tempo Brasileiro, 1997.

HESPANHA, António Manuel. O caleidoscópio do direito: o direito e a justiça nos dias e no mundo de hoje. Coimbra: Almedina, 2007.

JAKOBS, Günther. A imputação objetiva no direito penal. Trad. André Luís Callegari. São Paulo: Editora Revista dos Tribunais, 2000.

p. 42 e ss.

e MELIÁ, Canció. Derecho penal del enemigo. Madrid: Thomson Cívitas, 2003,

. Fundamentos do direito penal. Trad. André Luís Callegari. São Paulo: Editora Revista dos Tribunais, 2003.

LUHMANN, Niklas. Sociologia do Direito. V. I e II. São Paulo: Templo Brasileiro, 2001.

LUIZI, Luís. Os Princípios Constitucionais Penais. 2. ed. Aumentada. Porto Alegre: Sérgio Fabris, 2003.

MATUS, Jean Pierre. La transformación de la teoria del delito em el derecho penal internacional. Santiago: Ediciones Jurídicas de Santiago, 2008.

MIRANDA PEDRO, Manuel José. Algumas notas sobre a imputação objetiva no direito penal português: mais Roxin, menos Jakobs. Revista Portuguesa de Ciência Criminal, Coimbra, ano 17, n. 1, p. 7 e ss., 2007. 
PRADO, Luiz Regis. Bem Jurídico-penal e Constituição. 3. ed. rev. atual. e ampl.. São Paulo: RT, 2003.

(coordenador). Responsabilidade penal da pessoa jurídica: em defesa do princípio da imputação penal subjetiva. São Paulo: Editora Revista dos Tribunais, 2001.

e MENDES DE CARVALHO, Érika. Teorias da imputação objetiva do resultado: uma aproximação crítica a seus fundamentos. São Paulo: Editora Revista dos Tribunais, 2002.

RAWLS, John. Uma teoria da justiça. Trad. Carlos Pinto Correia. 2. ed. Lisboa: Presença, 2001.

RIPOLLÉS, Jose Luis Díez. Da sociedade do risco à segurança cidadã: um debate desfocado. Revista Portuguesa de Ciência Criminal, Coimbra, ano 17, n. 4, p. 547 e ss., 2007.

ROXIN, Claus. Funcionalismo e imputação objetiva no direito penal. Trad. e introdução de Luís Greco. Rio de Janeiro: Renovar, 2002.

SANTOS, Boaventura. Os processos da globalização. In: A Globalização e as Ciências Sociais. 2. ed. São Paulo: Cortez, 2002. p. 25-102

SANTOS, Cláudia. A mediação penal, a justiça restaurativa e o sistema criminal: algumas reflexões suscitadas pelo anteprojecto que introduz a "mediação penal de adultos" em Portugal. Revista Portuguesa de Ciência Criminal, Coimbra, ano 16, n. 1, p. 85 e ss., 2006.

SELIM DE SALES, Sheila Jorge. Princípio da Efetividade no Direito Penal e a importância de um conceito garantista do bem jurídico-penal. São Paulo: Revista dos Tribunais, v. 848, p. 416 e ss., junho de 2006.

SILVA DIAS, Augusto. Ramos emergentes do Direito Penal relacionados com a proteção do futuro (ambiente, consumo e genética humana). Coimbra: Coimbra, 2008.

SILVA, José Afonso. Curso de direito constitucional positivo. 9. ed. São Paulo: Malheiros, 1992.

VON LISZT, Franz. Tratado de derecho penal. Trad. Luís Jimenez de Asúa. 3. ed. Madrid: Réus, t. 2 